\title{
Compreender as Representações Sociais na Depressão Pós-Parto nas Redes Sociais
}

\author{
Simone do Nascimento Idalino ${ }^{1}$, Amanda Castro ${ }^{2}$
}

\begin{abstract}
RESUMO
Este trabalho tem por objetivo compreender quais são as representações sociais acerca da depressão pós-parto postadas nas redes sociais. Esta pesquisa é de caráter qualitativo, do tipo exploratória e documental, realizada por meio de postagens e comentários no facebook dentro de grupos cuja centralidade é a depressão pós-parto. A partir dos relatos on-line de mães, foi formado um corpus de análise com auxílio do software IrAMuTeQ 0.7. A partir desse corpus foi realizada uma classificação hierárquica descendente, que permite uma análise lexical do material textual e fornece contextos (classes lexicais), destacada por um vocabulário específico e pelos segmentos de textos em que essas palavras se inserem. Os resultados obtidos permitem inferir que as representações sociais acerca da depressão pós-parto nas redes sociais refletem a ideia de que a ausência de apoio entre familiares, conflitos familiares, a presença de sofrimento psíquico ou dependência química na família e a falta de vínculo, são fatores que influenciariam na ocorrência da depressão pós-parto, o que remete à relevância da família e do apoio social enquanto estratégia de promoção de saúde. Nesse sentido, programas sociais e de saúde devem levar em consideração a presença da família no processo de promoção e prevenção em saúde da mulher.
\end{abstract}

Palavras-chave: Depressão pós-parto. Família. Redes sociais. Saúde.

\section{UNDERSTANDING SOCIAL REPRESENTATIONS IN POSTPARTUM DEPRESSION IN SOCIAL NETWORKS}

\section{ABSTRACT}

This paper aims to understand the social representations of postpartum depression in social networks. This research is qualitative, exploratory, and documentary, researched through facebook posts and comments, within groups on postpartum depression. From the reports of online mothers, an analysis corpus was formed with the aid of IrAMuTeQ 0.7 software. From this corpus, a descending hierarchical classification was performed, that allows a lexical analysis of the textual material, maintains contexts (lexical classes), highlighted by a specific vocabulary and by the text patterns in which these words are inserted. The results show that the social representations of postpartum depression in social networks bring the idea that the lack of support among family members, family conflicts, the presence of psychological distress or chemical dependence in the family and the lack of bond are variables that would influence in the occurrence of postpartum depression, which refers to the relevance of family and social support as a health promotion strategy. In this sense, social and health programs should take into account the presence of the family in the process of promotion and prevention in women's health.

Keywords: Postpartum Depression. Family. Social networks. Cheers.

RECEBIDO EM: 11/12/2019

MODIFICAÇÕES SOLICITADAS EM: 20/3/2020

ACEITO EM: 30/3/2020

\footnotetext{
${ }^{1}$ Graduação em Psicologia pela Universidade do Extremo Sul Catarinense (2019). http://lattes.cnpq.br/1953086255399038. https://orcid.org/0000-00034550-300X. simone_idalino@hotmail.com

2 Doutorado em Psicologia pelo Programa de Pós-Graduação da Universidade Federal de Santa Catarina. Mestrado em Psicologia - UFSC. Psicodramatista formada pela escola Viver Psicologia Psicodrama. Especialista em Psicodrama pelo Centro Universitário Amparense - Unifia. Didata e Supervisora em Psicodrama. Especialista em Psicologia do desenvolvimento pela Universidade de Araraquara - Uniara. Psicóloga formada pela Universidade do Sul de Santa Catarina. Membro do Laccos - Laboratório de Psicologia Social da Comunicação e Cognição. Membro do Nupac-ST - Núcleo de Promoção e Atenção Clínica a Saúde do Trabalhador. Professora na Universidade do Extremo Sul Catarinense - Unesc. http://lattes.cnpq.br/1731586191596114. https://orcid.org/00000002-8666-4494.amandacastrops@gmail.com
} 


\section{INTRODUÇÃO}

A depressão pós-parto (DPP) no Manual de Diagnóstico e Estatística dos Transtornos Mentais (DSM-V) contém um especificador: o diagnóstico deve ser realizado da gestação até quatro semanas após o parto, sendo utilizado o termo periparto, enquanto o Código Internacional de Doença (CID 10) considera o momento de diagnosticar até seis semanas após o parto e denomina este período como pós-natal (FREITAS; SILVA; BARBOSA, 2016).

A depressão pós-parto (DPP), também conhecida como depressão puerperal, pode ser conceituada como um episódio de depressão maior que ocorre nas primeiras semanas após o parto. A Depressão Pós-Parto tem prevalência entre $10 \%$ a $15 \%$, porém menos de $25 \%$ das puérperas acometidas têm acesso ao tratamento, e somente $50 \%$ dos casos de depressão pós-parto são diagnosticados (OLIVEIRA; DUNNINGHAM, 2015).

Além disso, a DPP também pode ser diferenciada do blues puerperal, ou baby blues, caracterizado por alterações de humor, com intensidade leve a moderada, juntamente com sensação de tristeza, crises de choro, ansiedade, diminuição da concentração, irritabilidade e insônia. Esses sintomas costumam aparecer nas primeiras semanas de pós-parto, com um pico no quinto dia e resolução em duas semanas. A psicose puerperal, entretanto, costuma iniciar no puerpério, e apresenta alucinações visuais e/ou auditivas e delírios quanto à morte do bebê, além de negação do nascimento, infanticídio e agitação (OLIVEIRA; DUNNINGHAM, 2015; BRASIL, 2012).

Ainda, os sintomas da DPP são muito semelhantes a outras formas de depressão e podem ser caracterizados por distúrbio de humor depressivo, associado a desânimo persistente, ausência de prazer em atividades que antes apreciava, alterações do sono, irritabilidade, perda de apetite, cansaço, culpa e perda da libido. Além desses sintomas, também é comum que a nova mãe tenha uma sensação de inadequação e inabilidade para cuidar do seu filho, temor em machucar o bebê e, em alguns casos, há desinteresse pela criança. Podem apresentar também crises de choro, retraimento social, ideias obsessivas, crises de pânico e diminuição do grau de funcionamento mental (BOTH et al., 2016; GUEDES-SILVA, 2016; LOBATO; MORAES; REICHENHEIM, 2011).

A DPP não pode ser considerada uma condição clínica homogênea, pois há variações tanto no início quanto na gravidade e evolução dos sintomas. O início dos sintomas, para a maioria das mulheres, ocorre nos três primeiros meses após o parto, contudo é comum um segundo pico de incidência de sintomas depressivos entre o sexto e o oitavo mês após o parto (MILGROM; MARTIN; NEGRI, 1999).

Em alguns casos, as mulheres apresentam sintomas depressivos ainda durante a gravidez. Além disso, muitas mulheres que têm os sintomas de DPP já na gravidez apresentam também no período de pós-parto (FRIZZO et al., 2019). Quanto à evolução dos sintomas, a cronicidade da DPP tende a se prolongar, posto que entre $30 \%$ e $50 \%$ das mulheres continuam com os sintomas após seis meses (COOPER; MURRAY, 1995), o que se assemelha à duração de episódios depressivos em outros períodos e contextos de vida (FONSECA; CANAVARRO, 2017).

Como já citado, a DPP é clinicamente semeIhante a outros tipos de depressão em razão dos seus sintomas, porém existem evidências específicas da condição clínica da DPP que as mulheres podem apresentar, como preocupações exageradas com o bem-estar do seu filho, preocupações desproporcionais com a competência parental, grande labilidade emocional, medo intenso de ficar sozinha com a criança, de sair com ela e a machucar, associação de sintomas ansiosos com os sintomas depressivos, pensamentos obsessivos sobre machucar a criança, queixas físicas excessivas, dificuldade de concentração, dificuldade em tomar decisões, baixa probabilidade de ideação suicida e dificuldade em estabelecer ligações com o bebê (FONSECA; CANAVARRO, 2017; RIECHER-ROSSLER; HOFECKER, 2003).

$\mathrm{O}$ que pode acontecer é que o quadro sintomatológico pode ser desenvolvido em virtude das mudanças intensas nos níveis hormonais, comuns no período de pós-parto, juntamente com o stress do parto e as novas funções atribuídas pela maternidade, questões que podem dificultar o diagnóstico (SIT; WISNER, 2009; CANTILINO et al., 2010; PRENOVEAU et al., 2013).

Nesse contexto, o diagnóstico de depressão pós-parto é muito difícil de ser realizado pelos sintomas já citados, que são comuns no período de puerpério; situação que também ocorre porque os sintomas são semelhantes a transtornos de humor que surgem em outros períodos da vida, mas que podem ter início nas primeiras semanas após o parto e se intensificam nos seis meses seguintes, principalmente quando acompanhados de perda de interesse nas atividades cotidianas e humor depressivo por, no mínimo, duas semanas (BOTH et al., 2016).

Os fatores mais citados para o desenvolvimento da depressão pós-parto são as condições sociais impostas às mulheres, que não têm suporte familiar 
para lidar com essas questões. Há a dificuldade por parte da família e da própria puérpera em perceber a sintomatologia, que pode ser interpretada de forma equivocada (TEMÓTEO et al., 2018). A falta de espaços relacionais dialógicos, seja com a família, amigos ou especialistas, afeta a produção de recursos subjetivos para lidar de maneira saudável com a experiência da maternidade, incidindo na aceitação das normativas cultivadas socialmente sobre como deve ser uma mãe. A depressão pós-parto, portanto, não pode ser reduzida a aspectos biológicos. É preciso dicorrer igualmente sobre a trama intersubjetiva que constitui esse fenômeno (CESARIO; GOULART, 2018).

No contexto brasileiro, a prevalência de possíveis casos de depressão é de 26,3\%. Quanto aos fatores de risco sociodemográficos e individuais comuns no Brasil, estes são: pele parda, classe econômica baixa, histórico de uso de álcool e de transtornos mentais, uma gravidez não planejada, cuidados precários no nascimento ou no período de recém-nascido (DOMINGUES et al., 2015).

A gravidez não planejada é um fator que surge associado a $80 \%$ dos estudos avaliados por Temóteo et al. (2018). Quando se trata da baixa escolaridade e estado civil casada ou com companheiro, os trabalhos avaliados passam para $60 \%$. Fatores de risco para depressão, história pregressa de depressão, juntamente com a renda familiar, correspondem a $40 \%$ dos estudos, e $20 \%$ destes associam primíparas juntamente com alternância hormonal ao desenvolvimento da doença, com relevância confirmada ainda no pré-natal (TEMÓTEO et al., 2018).

Nessa situação, a assistência adequada dos profissionais da saúde desde o início da gestação, juntamente com o acompanhamento pré-natal, são essenciais para o controle da depressão pós-parto e também para a prevenção da mesma. Com esse acompanhamento é possível identificar fatores fisiológicos, como a já citada alternância hormonal, sendo o mais comum a queda dos níveis de progesterona quando a função tireoidiana está reduzida. Essas mudanças físicas podem abalar a mulher psicologicamente (TEMÓTEO et al., 2018).

Ainda sobre os fatores de risco, diversos eventos e situações que já estão estabelecidos propiciam o surgimento de problemas físicos, psicológicos e sociais, que se tornam mais intensos no período da gravidez e pós-parto. Os fatores mais discutidos na literatura mundial agrupam-se em três categorias: fatores de risco e proteção psicossociais, fatores de risco e proteção sociodemográficos/contextual e fatores de risco e proteção físicos. Cada uma dessas categorias possui subcategorias (ARRAIS; ARAÚJO; SCHIAVO, 2018).
A categoria fatores de risco psicológico/psiquiátrico corresponde a histórico de episódios depressivos anteriores ao período de gestação, estresse e/ou ansiedade durante a gestação, histórico anterior de DPP, antecedentes psiquiátricos, histórico familiar de transtornos mentais, idealização da maternidade e insatisfação com a gravidez. Por outro lado, esses fatores de proteção psicológicos podem ser minimizados com a participação em programas pré-natais com uma abordagem psicológica, que facilitam uma relação saudável entre as gestantes.

A categoria fatores de risco e proteção sociodemográficos/contextual englobam conflitos e insatisfação com sua relação conjugal, falta de apoio do parceiro e social, exposição à violência por parceiro íntimo e/ou conflito familiar durante a gravidez e pós-parto, baixa escolaridade, desemprego e estar em situação de subemprego associado a alto status de escolaridade.

A categoria de fatores de risco físico/hormonal e obstétrico corresponde à história de síndrome pré-menstrual, desregulação hormonal e citosinas inflamatórias de anemia pós-parto. Também há situações de intercorrência médica durante a gestação, gravidez não planejada, histórico de aborto espontâneo e parto cesariana. Outros fatores de risco são a não amamentação até oito semanas após o parto, não realizar acompanhamento pré-natal, problemas moderados ou graves no parto, analgesia, amamentação contínua e parto via vaginal (ARRAIS; ARAÚJO; SCHIAVO, 2018).

Desse modo, conhecer os fatores de risco de proteção da depressão pós-parto é importante, pois, assim, é possível planejar e executar ações preventivas e também a realização de triagem para as mulheres que apresentam esses fatores de risco, a fim de evitar que a depressão se instale. Quando se detecta a DPP no início do pós-parto ou até mesmo nas consultas pré-natais, é viável que se instale um tratamento adequado para essas mulheres visando à relação entre a mãe e o recém-nascido, e para, futuramente, possibilitar o equilíbrio psicológico do bebê (ARRAIS; ARAÚJO; SCHIAVO, 2018).

Nos primeiros meses de vida a criança é dependente dos cuidados maternos, portanto a mãe é responsável por funções básicas de ordem física e psicológica, como alimentação, cuidados de higiene, aquecer, proteger e interagir (OLIVEIRA; BRAGA, 2016). No momento de formação de vínculo entre a mãe e o bebê, ações comunicativas possibilitam trocas de informações e também sinais afetivos, que viabilizam o desenvolvimento e a aquisição de linguagem (OLIVEIRA; BRAGA, 2016). 
É, portanto, por meio da fala, dos toques e dos cuidados corporais com a mãe, que o recém-nascido é conduzido a se comunicar e expressar suas primeiras expressões de diálogo. Dessa maneira, caso a mãe dê respostas adequadas a essas expressões e atividades comunicativas exploratórias de seu filho, possibilita o processo de aquisição da fala e do vocabulário Ainda, na literatura encontram-se dados que mostram que a criança consegue diferenciar entonações vocais e as conectam a sentimentos vivenciados. Quando se trata de mães com DPP, é comum que estas tenham vocalizações baixas para responder aos bebês de até quatro meses. Também é comum apresentarem mais variações vocais e pausas e dificuldade em realizar entonações exageradas quando necessário, que é um importante fator para o desenvolvimento do vocabulário, e, posteriormente, para a comunicação e seus relacionamentos interpessoais (ARRAIS; ARAÚJO; SCHIAVO, 2018; OLIVEIRA; BRAGA, 2016).

Outro fator importante é a dificuldade de mães deprimidas em interagir com a criança de forma adaptativa, com menos disposição em responder de forma direta aos sinais da criança, além de estabelecer menos contato físico em comparação a mães não deprimidas (OLIVEIRA; BRAGA, 2016). A ausência de interação em casos de DPP podem acarretar expressões negativas nas características emocionais e comportamentais do bebê, menos expressões afetivas, maior ansiedade nos cuidados disponibilizados, maiores níveis de hostilidade, rejeição, negligência e agressividade (OLIVEIRA; BRAGA, 2016).

Diante desse quadro, compreende-se que a DPP influencia de forma significativa na qualidade da interação mãe-bebê, situação que repercute no desenvolvimento social e afetivo da criança e no seu processo de estruturação da linguagem. Por esse motivo, concebe-se a importância de se reconhecer e diagnosticar de forma precoce a doença em questão, a fim de prevenir os efeitos negativos que atingem a mãe e a criança; a primeira em sua estrutura biopsicossocial e a segunda em seu desenvolvimento global (OLIVEIRA; BRAGA, 2016; TEMÓTEO et al., 2018).

Outra questão importante trata-se de que fiIhos de mãe com DPP demonstram muita dificuldade em interações sociais e déficits na regulação dos estados afetivos. As repercussões precoces comuns são o baixo desempenho em testes de desenvolvimento e grandes níveis de apego inseguro; as repercussões tardias mais comuns são transtornos de conduta, comprometimento de saúde física, ligações inseguras e também episódios depressivos. Essas questões afetam diretamente na relação, afetividade e cuidados disponibilizados ao filho. Os filhos de mãe deprimidas possuem $29 \%$ de possibilidade em desenvolver desordens emocionais e comportamentais se comparados ao $8 \%$ de chance de crianças que não possuem mães deprimidas. Essas questões no primeiro ano de vida da criança são responsáveis pela baixa habilidade cognitiva da criança por volta dos quatro anos de idade, $\mathrm{e}$ também podem influenciar alterações de níveis neuroendócrinos, autonômicos e psicológicos (OLIVEIRA; BRAGA, 2016).

Nesse panorama é possível identificar, de forma característica, os impactos da DPP no desenvolvimento infantil, em que o padrão de interação estabelecido entre criança e mãe é internalizado pela criança na expressão de seus afetos e nos comportamentos e relacionamentos interpessoais e de interação por meio do brincar. Em consequência, a criança pode apresentar dificuldades na exploração do mundo e no potencial de entendimento, concentração, atenção e percepção. Essas circunstâncias também repercutem no bem-estar, desenvolvimento e crescimento da criança, que possibilitam a exploração do mundo por meio de sensações que afetam o equilíbrio e satisfazem as necessidades (OLIVEIRA; BRAGA, 2016).

Desse modo, a depressão pós-parto é uma produção subjetiva complexa que, para além de apenas aspectos biológicos e hormonais, é formada pela subjetividade da puérpera e pela subjetividade social, composta pelo discurso de especialistas da saúde, familiares e amigos, que ditam as experiências socialmente aceitáveis de maternidade e marginalizam as demais, o que pode gerar sentimentos de frustração e culpa que compõem a representação social dominante da depressão pós-parto (CESARIO; GOULART, 2018).

Dentre os resultados encontrados no estudo de Cesario e Goulart (2018), é possível destacar que a representação da depressão pós-parto ancora-se na romantização da maternidade, que, por sua vez, normatiza e favorece a idealização desse processo. Nesse contexto, a depressão pós-parto expressa a dissonância entre o ideal socialmente normatizado e a experiência real, vivida na singularidade. Nesse sentido, torna-se relevante esta pesquisa, que tem por objetivo compreender as representações sociais na depressão pós-parto nas redes sociais.

\section{METODOLOGIA}

Esta pesquisa caracterizou-se como qualitativa, do tipo exploratória e empírica. As metodologias de pesquisa qualitativa, segundo Minayo (2006, p. 2223), são "entendidas como aquelas capazes de incor- 
porar a questão do significado e da intencionalidade como inerentes aos atos, às relações e às estruturas sociais, [...] como construções humanas significativas". O processo exploratório da pesquisa diz respeito ao tempo dedicado às interrogações previamente realizadas acerca do objeto, e o seu foco principal é a elaboração do projeto de investigação. Permite, ainda, a exclusão ou confirmação de hipóteses e construção de teorias (MINAYO, 2001).

Tratou-se de uma pesquisa documental em que o documento escrito constitui uma fonte preciosa, insubstituível em qualquer reconstituição referente a um passado relativamente distante, permanecendo como o único testemunho de atividades ocorridas num passado recente ou em uma forma de registro das informações (CELLARD, 2008, p. 295)

Foram selecionados oito textos de postagens em um grupo público no Facebook sobre depressão pós-parto. Para se chegar nesse grupo foram utilizadas as palavras de busca "Depressão pós-parto e mãe", usando como filtro a busca por grupos públicos, ou seja, abertos a todos, sem a necessidade de aceite de convite. Foram encontrados 28 grupos a partir dos critérios de busca, dos quais apenas dois traziam a proposta da apresentação de relatos de mulheres. Dentre esses dois grupos optou-se por selecionar aquele com maior número de publicações semanais (dez publicações por semana), tendo em vista a necessidade de exploração dos conteúdos. Foram selecionadas as postagens e comentários presentes nos meses de fevereiro a junho de 2019. Optou-se por estas postagens em razão de seu caráter público, o que viabilizou o acesso da pesquisadora.

A partir dos relatos foi formado um corpus de análise com auxílio com software IrAMuTeQ 0.7. A partir desse corpus foi realizada uma classificação hierárquica descendente. De acordo com Camargo e Justo (2013), a CHD visa a obter classes de Segmentos de Texto (ST) que, ao mesmo tempo, apresentam vocabulário semelhante entre si e vocabulário diferente dos STs das outras classes. O software separou as palavras de maior frequência em classes, possibilitando que o pesquisador conseguisse resgatar o contexto de sentido das palavras, a fim de nomear e interpretar as classes.

Os nomes das participantes não foram revelados, para que não pudessem ser identificados os dados de autoria. As participantes, cujo relato foi selecionado, foram contatadas para fornecer o aceite on-line de um Termo de Consentimento Livre e Esclarecido. Evitou-se a caracterização das participantes nos resultados, também para evitar a identificação das mes- mas. A pesquisadora esteve atenta às recomendações sobre ética em pesquisa na internet, sendo, atualmente, norteadas pelas diretrizes de um grupo multicultural (Association of Internet Researchers - AolR).

\section{ANÁLISE E DISCUSSÃO DOS RESULTADOS}

O IrAMuTeQ classifica os segmentos de texto baseado no vocabulário, e o conjunto deles é repartido em classes pelo programa, com base na frequência das formas reduzidas (palavras já lematizadas). Após a divisão em classes, o programa possibilita, a partir das palavras selecionadas nas classes, a recuperação dos segmentos de textos correspondentes e a associação de cada um, o que permite o agrupamento das palavras estatisticamente significativas e a análise qualitativa dos dados (CAMARGO; JUSTO, 2013).

Os 24 textos (postagens e comentários) foram organizados em um único documento e passaram por classificação hierárquica descendente, ou seja, foram selecionadas as palavras com frequência maior ou igual a 3,96 e x2 igual ou maior que 3,84 (critério estabelecido pelo próprio programa). Em seguida, a pesquisadora resgatou os trechos em que estas palavras apareciam, dando nome às classes e analisando-as.

O programa separou os textos em 64 seguimentos de textos, dos quais, pelo critério de frequência, 49 foram selecionados. O programa dividiu o corpus em quatro classes, considerando de um lado as classes 3 e 4 e, de outro, as classes 1 e 2, conforme a Figura 1.

Figura 1 - Dendrograma do corpus DPP

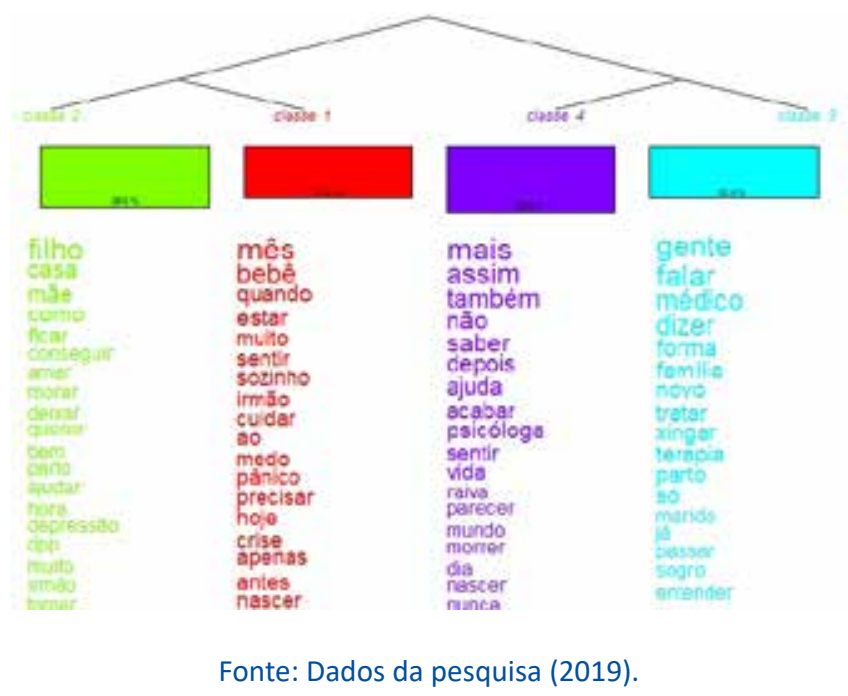

A classe 3, denominada "falta de apoio x violência obstétrica", apresenta $22,45 \%$ dos seguimentos de textos, trazendo palavras como gente, fala, médico e 
família. Nesta classe as mulheres mostram a dificuldade em falar para a família sobre o fato de fazer terapia. A palavra médico faz menção à violência obstétrica que envolve xingar, amarrar e a negligência na procura em situação de crise. Desta forma, a depressão pós-parto, para estas mães internautas, envolve falta de apoio familiar durante a psicoterapia, carência de apoio durante e após o parto e violência obstétrica. Segue a fala de uma participante: "Gente, nunca sofri na minha vida do que durante o parto; fora as traições do meu marido; o parto foi horrível, o médico me amarrou, a bolsa não tinha estourado, o médico tirou antes da hora, me xingava".

No Brasil, ainda não existe uma lei específica que reconheça a Violência Obstétrica como uma violação dos direitos das mulheres. A expressão "violência obstétrica" (VO), de acordo com Tesser et al. (2015), é utilizada para descrever e incluir diversas formas de violência durante a prática obstétrica profissional. Ela inclui desde maus tratos físicos até psicológicos e verbal. Também podemos acrescentar os procedimentos desnecessários e danosos, como casos como episiotomias, restrição ao leito no pré-parto, clister, tricotomia, ocitocina de rotina e ausência de acompanhante. Tais procedimentos danosos podem afetar o estado emocional da mãe, influenciando, junto a outros fatores, na depressão pós-parto (TESSER et al., 2015).

O parto humanizado ocorre quando os desejos das mulheres são respeitados e quando ela se sente o mais confortável possível para trazer seu filho ao mundo, segura e acolhida pelos profissionais. As mulheres não recebem as informações de que têm direito a um parto acolhedor quando se trata de realizar o procedimento cirúrgico. $\mathrm{O}$ acolhimento e o respeito proporcionado a essas mães neste momento tão significativo, possibilita para as mesmas e seus bebês melhores condições durante e após o parto. A violência obstétrica, entretanto, ainda se faz presente e o parto humanizado infelizmente não constitui um direito acessível a todas (MABUCHI; FUSTINONI, 2008).

A naturalização da violência obstétrica e a falta de apoio familiar podem levar as mulheres a se sentirem desconfortáveis no papel de mãe. A violência sofrida no âmbito médico e social pode ser interpretada pela mulher como uma ausência de valor da maternidade, e pode, inclusive, afetar sua relação consigo mesma. Torna-se necessário, portanto, ampliar o suporte psicoterápico a mulheres antes e após o parto, posto que este deve ter como prerrogativa a humanização (MABUCHI; FUSTINONI, 2008).
A classe 4, chamada "Quem eu sou como mãe", apresenta $28,57 \%$ dos seguimentos dos textos, trazendo as palavras psicólogo, raiva, sentir, ajuda e vida. A palavra vida surge para falar do desejo de morrer durante a DPP. A palavra raiva vem para expressar os sentimentos ao ver uma mulher grávida ou um bebê recém-nascido. A palavra sentir faz referência a não sentir amor e não sentir-se a mesma pessoa. A palavra psicólogo e ajuda faz referência à necessidade de buscar tratamento. Assim, a DPP parece envolver uma raiva do estágio gestacional e puerpério, uma dificuldade de acessar sentimentos positivos, uma perda de identidade em relação ao novo papel, o que pode gerar ideação suicida. Segue um trecho de uma postagem: "Toda vez que vejo uma grávida ou uma mulher que teve um bebê, sinto uma raiva e uma revolta que não sei explicar, não aguento mais sentir isto".

Durante o pré-natal nota-se que a ansiedade impactante da notícia sobre a gestação passa a ser dividida em trimestres, quando nesses primeiros três meses aparecem os desconfortos por causa das primeiras alterações físicas. $O$ medo de perder o bebê e o aumento da irritabilidade são bastante comuns. Durante o segundo trimestre ocorre certo impacto em razão da percepção da existência do filho, e a ansiedade começa a aumentar; por fim, no terceiro trimestre, as aflições aumentam pela proximidade do parto e pela formação de um novo papel constituinte da identidade da mulher. $O$ desenvolvimento desses fatores é importante para que os familiares e os profissionais que acompanham a gestante estejam atentos para as características comuns que aparecem nestas fases, criando condições para uma escuta de qualidade, a fim de acolher a diversidade dos mais diversos sentimentos que podem acontecer. A ambivalência afetiva precisa ser acolhida e respeitada para que haja a redução do impacto psicológico nessa transição para novos papéis (SARMENTO; SETÚBAL, 2003). A qualidade da experiência desse processo é subjetiva, individual, extrapolando, portanto, a dimensão sintomatológica, que não dá visibilidade ao aspecto emocional, singular e político-social, que desconsidera o sujeito que vivencia o fenômeno (CESARIO; GOULART, 2018).

Tanto a mulher quanto a família/acompanhante precisam ser vistas como seres humanos integrais e indivisíveis, com autonomia e participação no processo de gerar e parir um filho. A gestação e o parto de um filho não constroem por si só o papel de mãe. Este é construído com base nas referências afetivas de cuidado. Nesse sentido, a vivência de um estado de desamparo pode conduzir a mãe a uma dificuldade de vinculação com o seu filho. Essa, por estar exposta a 
riscos, sejam de complicações cirúrgicas ou de danos emocionais, necessita de cuidados singulares, que englobam a busca pelo suporte psicológico e social durante esse período de ajuste identitário. Desse modo, inicialmente a mulher necessita da validação do seu direito de se cansar, de ter raiva, para, posteriormente, poder procurar apoio social para compreender o papel de mãe (CARRARO et al., 2008).

A classe 1 , denominada "Medo da crise", apresenta $22,45 \%$ dos seguimentos dos textos, trazendo palavras como mês, bebê, sozinha, cuidar e medo. As mães trazem relatos do medo associado à crise de pânico, posto que estas aconteciam enquanto tinham de cuidar do bebê, o que aumentava a preocupação. Além disto, as participantes trouxeram a dificuldade de ficar sozinha com o bebê quando se tem crise de pânico que duram meses, o que, segundo as internautas, atrapalha o vínculo mãe e bebê. Segue o exemplo de postagem: "Também tinha ataques de pânico, sentia que nunca iria conseguir mais ficar sozinha com a bebê".

Algumas mulheres apresentam um aumento sintomatológico que exacerba a crise de pânico no final da gravidez. Isso ocorre tendo em vista que alterações fisiológicas associadas à gestação podem resultar em ocasionais taquicardias, sudorese, tonturas e encurtamento da capacidade para inspirar. Tais sintomas podem ser interpretados pelas mulheres de maneira catastrófica, influenciando na ocorrência de crises de pânico completas ou incompletas (CANTILINO et al., 2010).

Além disso, considerando a normatização do que é ser mãe, a representação social disso pode afetar no medo da falta de capacidade para o exercício deste papel. A mulher passa a acreditar que não possui os atributos conferidos socialmente ao papel de mãe; se sente impotente e incapaz, o que pode gerar a sensação de ansiedade ou o sentimento de raiva (CESARIO; GOULART, 2018).

Lowen (1997) traz a raiva como uma das principais formas de lidar com a crise de pânico. Segundo o autor, o paciente enraivecido precisa experienciar o descontrole. Tendo em vista que um dos principais sintomas do Transtorno do Pânico é justamente o medo de perder o controle (LOWEN, 1997), a mulher precisa abrir mão desse controle para deixar fluir o sentimento de raiva experienciado durante a gravidez e ao longo de sua vida, o que possibilita a descoberta da mãe possível de se ser, não mais da mãe idealizada (AZEVEDO; ARRAIS, 2006).
A classe 2, denominada "ambivalência afetiva", apresenta $26,53 \%$ dos seguimentos dos textos e traz palavras como filho, casa, mãe, morar, amar. As palavras morar e casa fazem referência a morar com familiares para obter apoio durante a depressão pós-parto. A palavra mãe destaca dificuldades das participantes com a mãe, quando estas têm problemas psicológicos, com drogas ou quando esta não tem um bom vínculo com a filha. A palavra amor diz respeito à ambivalência afetiva, em que se ama estar com os filhos, mas se odeia ser mãe. Segue uma postagem como exemplo: "Amo ficar com meu filho, mas estou muito cansada desta vida de ser mãe, eu odeio".

Quando nasce um filho, a maioria das mulheres experimenta sentimentos ambivalentes em relação à imagem idealizada de maternidade na norma cultural. Deste modo, ocorre um conflito entre o ideal e o real, que pode desencadear sofrimento psíquico que, por sua vez, pode conduzir para a depressão após o parto (AZEVEDO; ARRAIS, 2006).

Outro fator relacionado à DPP diz respeito ao histórico familiar (SARAIVA; COUTINHO, 2008). A maternidade não inicia apenas com a chegada de um bebê, mas, sim, muito antes disso. Pode estar vinculada às primeiras relações e identificações da mulher, nas brincadeiras infantis e na fase da adolescência, aprimorando-se com o desejo de ter um filho até a gravidez em si. Nesse contexto, o uso de alcool e drogas durante a maternidade surge como fator de risco para o desenvolvimento posterior de depressão pós-parto, seja por questões fisiológicas ou pela abstinência em relação à dependência emocional (SILVA et al., 2019). Durante esta fase podem ressurgir conflitos até então não elaborados pela mãe, além de esta reviver experiências anteriores que podem ter sido dolorosas ou apaixonantes. Desse modo, com uma gestação, a mulher está num período no qual fica mais sensível a esses fatores sociais e familiares, podendo estar mais suscetivel a transtornos emocionais. Nesse contexto, a psicopatologia na maternidade engloba um processo que envolve várias gerações familiares - a chamada transmissão transgeracional. Assim, a presença de uma mãe com sofrimento psíquico, ou na condição de dependência química (SILVA et al., 2019), pode gerar danos emocionais na filha que, quando na condição de mãe, poderá apresentar DPP (PICCININI et al., 2008).

Em seguida, para finalizar, realizou-se análise de similitude, que avalia as ocorrências entre as palavras. A ilustração dessa análise consta na Figura 2. 
Figura 2 - Árvore de palavras

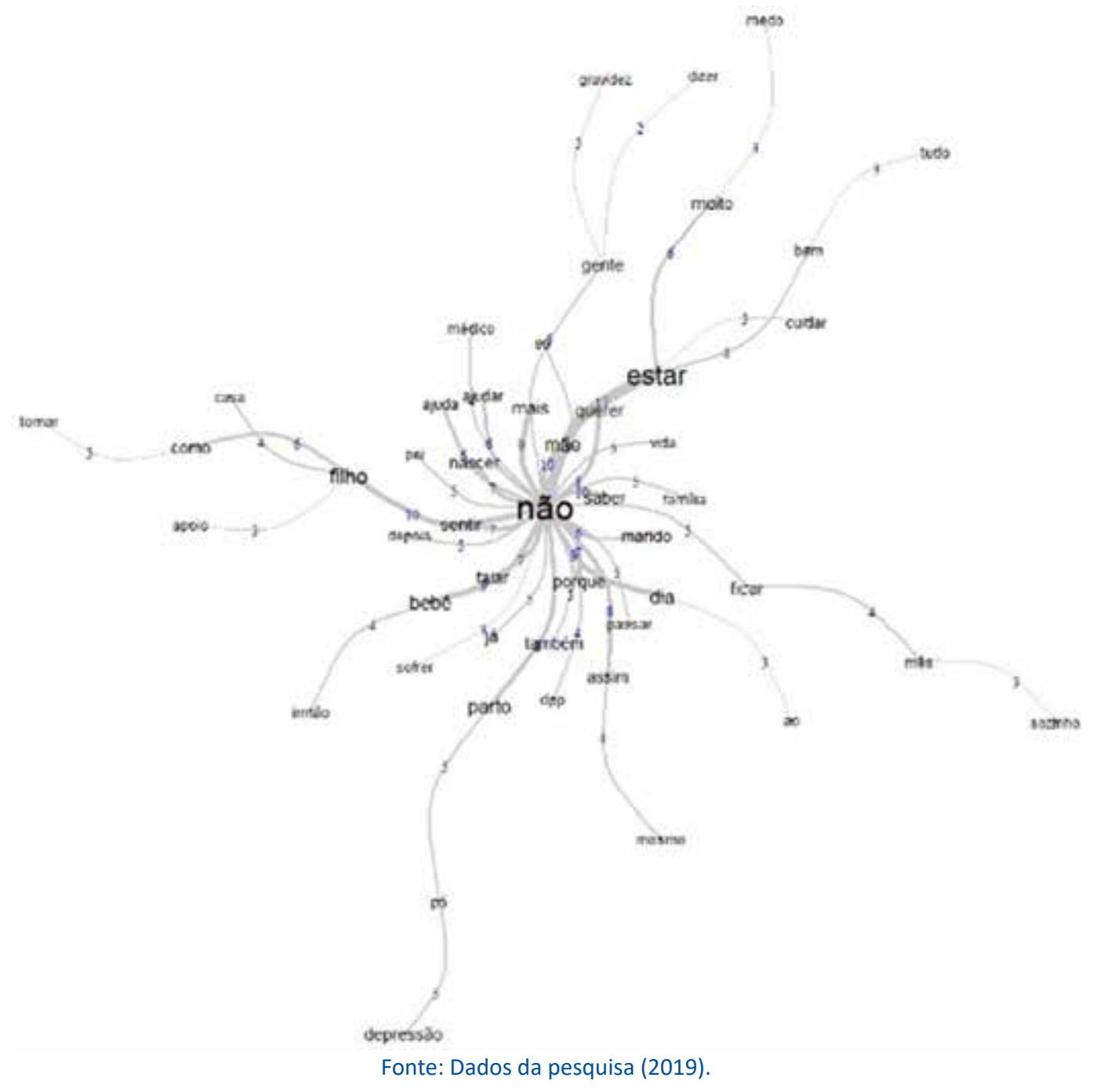

No centro, a palavra não apresenta a maior frequência associada a bebê, filho, nascer, sentir, família, marido, pai, mãe, saber, ajuda. Deste modo, a DPP parece uma negação da maternidade associada à ausência dos sentimentos que, socialmente, se espera nesta função. Também surge relacionada à falta de marido, pai, de ajuda e de conhecimento. Sim, a DPP é algo que envolve não apenas a mulher, mas uma negligência social e familiar que não lhe ajuda a desenvolver este novo papel.

\section{CONSIDERAÇÕES FINAIS}

Este trabalho teve por objetivo principal compreender as representações sociais na depressão pós-parto nas redes sociais. Também podemos, entre esses objetivos, discutir as crenças presentes nas postagens sobre depressão pós-parto, a identificação nos textos das redes sociais dos aspectos que caracterizem a depressão pós-parto e, por fim, foram relacionadas as representações sociais da depressão pós-parto nas redes sociais, com o conhecimento especializado presente em artigos da área.

Os resultados obtidos denotam que as representações sociais da depressão pós-parto nas redes sociais trazem a ideia de que a ausência de apoio entre familiares, conflitos familiares, a presença de sofrimento psíquico ou dependência química na família e a falta de vínculo, são variáveis que influenciariam na ocorrência da depressão pós-parto, o que remete à relevância da família e do apoio social enquanto estratégia de promoção de saúde. Nesse sentido, programas sociais e de saúde devem levar em consideração a presença da família no processo de promoção e prevenção em saúde da mulher.

As crenças a respeito da depressão pós-parto nas redes sociais englobaram a ambivalência afetiva, em que a maternidade envolveria sentimentos positivos e negativos. Torna-se necessário pensar em estra- 
tégias grupais que permitam a essas mães viverem a maternidade real, sem a idealização deste papel, que conduz à constante frustração. Desse modo, sugerem-se novas pesquisas que abranjam como se caracteriza a ambivalência afetiva entre mães.

Além disso, para as mães internautas, tal qual previsto na fundamentação teórica, a falta de apoio familiar durante a psicoterapia, a ausência de apoio durante e após o parto e a violência obstétrica, seriam fatores que influenciariam na ocorrência da depressão pós-parto. Na psicoterapia, portanto, é importante envolver familiares e rede social de apoio, para que, antes-durante e pós o parto, a mulher não se sinta sozinha e vulnerável em razão da falta de apoio; apoio este relevante inclusive para coibir a violência obstétrica.

Assim, a DPP parece envolver uma raiva do estágio gestacional e puerpério, uma dificuldade de acessar sentimentos positivos, uma perda de identidade em relação ao novo papel, e o medo de entrar em crise. Torna-se relevante considerar que o papel de mãe não é instintivo, tampouco biológico; há variáveis culturais e sociais que implicam o exercício deste papel e que podem afetar na sensação de capacidade da mulher ante os desafios da maternidade. As crenças sociais afetam as práticas das mulheres, e as práticas das mulheres, por sua vez, afetam igualmente as representações. A discussão sobre a maternidade possível e um pré-natal mais humanizado pode possibilitar o mapeamento dessas crenças, para que no interior dos grupos sociais seja possibilitado discutir as maternidades possíveis e a maternidade não desejada.

\section{REFERÊNCIAS}

ARRAIS, Alessandra da Rocha; ARAUJO, Tereza Cristina Cavalcanti Ferreira de; SCHIAVO, Rafaela de Almeida. Fatores de risco e proteção associados à depressão pós-parto no pré-natal psicológico. Psicologia: Ciência e Profissão, v. 38, n. 4, p. 711-729, 2018.

AZEVEDO, K. R.; ARRAIS, A. R. O mito da mãe exclusiva e seu impacto na depressão pós-parto. Psicologia: Reflexão $e$ Crítica, v. 19, n. 2, p. 269-276, 2006.

BOTH, C. T. et al. Depressão pós-parto na produção científica da enfermagem brasileira: revisão narrativa. Revista Espaço Ciência \& Saúde, v. 4, n. 1, p. 67-81, 2016.

BRASIL. Ministério da Saúde. Cadernos de Atenção Básica: atenção ao pré-natal de baixo risco. Departamento de Atenção Básica. Brasília: Editora do Ministério da Saúde, 2012.

CAMARGO, B. V.; JUSTO, A. M. Iramuteq: um software gratuito para análise de dados textuais. Temas em Psicologia, v. 21, n. 2, p. 513-518, 2013.
CANTILINO, A. et al. Postpartum depression in Recife-Brazil: prevalence and association with bio-socio-demographic factors. Jornal Brasileiro de Psiquiatria, Rio de Janeiro, v. 59, n. 1, p. 1-9, 2010.

CARRARO, T. E. et al. O papel da equipe de saúde no cuidado e conforto no trabalho de parto e parto: opinião de puérperas. Texto \& Contexto Enfermagem, Florianópolis, v. 17, n. 3, p. 502-509, 2008.

CELLARD, A. A análise documental. In: POUPART, J. et al. $A$ pesquisa qualitativa: enfoques epistemológicos e metodológicos. Petrópolis, Vozes, 2008. p. 295-316.

CESARIO, Rafaella Pinheiro; GOULART, Daniel Magalhães. Depressão pós-parto para além do diagnóstico: representações sociais e subjetividade. Revista Subjetividades, v. 18, n. 1, p. 79-91, 2018.

COOPER, P. J.; MURRAY, L. Course and recurrence of postnatal depression: evidence for the specificity of the diagnostic concept. The British Journal of Psychiatry, v. 166, n. 2, p. 191-195, 1995.

DOMINGUES, R. M. S. M. et al. Adequação da assistência pré-natal segundo as características maternas no Brasil. Revista Panamericana de Salud Pública, v. 37, p. 140-147, 2015.

FONSECA, A.; CANAVARRO, M. C. Depressão pós-parto. Propsico: Programa de Atualização em Picologia Clínica e da Saúde - Ciclo 1, 2017. p. 111-164. Disponível em: https://estudogeral.uc.pt/bitstream/10316/45085/1/Capitulo_Depressaoposparto_AFonseca.pdf. Acesso em: 14 ago. 2019.

FREITAS, M. E. S.; SILVA, F. P.; BARBOSA, L. R. Análise dos fatores de risco associados à depressão pós-parto: revisão integrativa. Revista de Atenção à Saúde, São Caetano do Sul, v. 14, n. 48, p. 94-98, 2016.

FRIZZO, Giana Bitencourt et al. Maternidade adolescente: a matriz de apoio e o contexto de depressão pós-parto. Psicologia: Teoria e Pesquisa, v. 35, jul. 2019.

GUEDES-SILVA, Damiana. Depressão pós-parto: prevenção e conseqüências. Revista Subjetividades, v. 3, n. 2, p. 439450, 2016.

LOBATO, G.; MORAES, C. L.; REICHENHEIM, M. E. Magnitude da depressão pós-parto no Brasil: uma revisão sistemática. Revista Brasileira de Saúde Maternal e Infantil, Recife, v. 11, n. 4, p. 369-379, out./dez. 2011.

LOWEN, Alexander. Raiva: a emoção que cura. São Paulo: Summus, 1997.

MABUCHI, A. S.; FUSTINONI, S. M. The meaning given by the healthcare professional to labor and humanizing delivery. Acta Paulista de Enfermagem, on-line, v. 21, n. 3, p. 420-426, 2008.

MILGROM, J.; MARTIN, P. R.; NEGRI, L. M. Treating postnatal depression: A psychological approach for health care practitioners. Chichester: Wiley, 1999.

MINAYO, M. C. S. Pesquisa social: teoria, método e criatividade. 18. ed. Petrópolis: Vozes, 2001. 
MINAYO, M. C. S. Pesquisa avaliativa por triangulação de métodos. Avaliação qualitativa de programas de saúde: enfoques emergentes. São Paulo: Vozes, 2006.

OLIVEIRA, M. J. M.; DUNNINGHAM, W. A. Prevalência e fatores de risco relacionados à depressão pós-parto em Salvador. Revista Brasileira de Neurologia e Psiquiatria, v. 19, n. 2, 2015.

OLIVEIRA, A. P.; BRAGA, T. de L.. Depressão pós-parto: consequências para mãe e o recém-nascido-uma revisão sistemática. Revista Eletrônica Estácio Saúde, v. 5, n. 1, p. 133144, 2016.

PICCININI, C. A. et al. Gestação e constituição da maternidade. Psicologia em Estudo, Maringá, v. 13, n. 1, p. 63-72, jan./mar. 2008.

PRENOVEAU, J. et al. Postpartum GAD is a risk factor for postpartum MDD: the course and longitudinal relationships of postpartum GAD and MDD. Depression and Anxiety, v. 30, n. 6, p. 506-514, 2013.

RIECHER-RÖSSLER, Anita; HOFECKER FALLAHPOUR, M. Postpartum depression: do we still need this diagnostic term?. Acta Psychiatrica Scandinavica, v. 108, p. 51-56, 2003.

SARAIVA, E. R. A.; COUTINHO, M. P. L. O sofrimento psíquico no puerpério: um estudo psicossociológico. Revista Mal-Estar e Subjetividade, Fortaleza, v. 8, n. 2, p. 505-527, jun. 2008.

SARMENTO, R.; SETÚBAL, M. S. V. Abordagem psicológica em obstetrícia: aspectos emocionais da gravidez, parto e puerpério. Revista Ciência Médica, Campinas, v. 12, n. 3, p. 261-268, jul./set. 2003.

SILVA, Cristina Rejane Alves et al. Depressão pós-parto: a importância da detecção precoce e intervenções de enfermagem. ReBIS - Revista Brasileira Interdisciplinar de Saúde, v. 3, n. 1, 2019.

SIT, Dorothy K.; WISNER, Katherine L. The identification of postpartum depression. Clinical obstetrics and gynecology, v. 52, n. 3, p. 456, 2009.

TEMÓTEO, M. P. et al. Fatores associados à depressão pós-parto e instrumento para o diagnóstico precoce. In: JORNADA DE INICIAÇÃO CIENTÍFICA, 3. e SEMINÁRIO CIENTÍFICO DA FACIG - SOCIEDADE E TECNOLOGIA, 4., 2018, Minas Gerais. Anais [...]. Minas Gerais: Facig, 2018. p. 1-5. Disponível em: http://www.pensaracademico.facig.edu.br/index. $\mathrm{php} /$ semiariocientifico/article/view/757/660. Acesso em: 13 ago. 2019.

TESSER, C. D. et al. Violência obstétrica e prevenção quaternária: o que é e o que fazer. Revista Brasileira de Medicina de Família e Comunidade, Rio de Janeiro, v. 10, n. 35, p. 1-12, 2015. 